\title{
Social media: the way forward or a waste of time for physicians?
}

\author{
${ }^{1} \mathrm{M}$ DeCamp, ${ }^{2} \mathrm{AM}$ Cunningham \\ ${ }^{1}$ Assistant Professor, Berman Institute of Bioethics and Division of General Internal Medicine, Johns Hopkins University, Maryland, USA; \\ ${ }^{2}$ Clinical Lecturer, Institute of Medical Education, Academic Lead for eLearning, School of Medicine, Cardiff University, Heath Park, Cardiff, \\ Wales
}

ABSTRACT Social media is everywhere; its use has grown exponentially over recent years. The prevalence of these outlets for communication raises some interesting and potentially risky issues for physicians. On the one hand, some believe that physicians should have a strong social media presence and can benefit greatly from access to a global community of peers and leaders through blogs, online forums, Facebook, Twitter and other communication channels. Dr Anne Marie Cunningham provides a strong case for the advantages of developing networks and figuring out who and what to pay attention to online.

On the other hand however, others believe that the use of social media places doctors at a professional and ethical risk and is essentially a waste of time for the already time-pressured physician. Professor DeCamp argues that the risks of social media outweigh their benefits. It makes it more difficult to maintain a distinction between private and professional personas, and as we have seen, one mistyped or inappropriate comment can have potentially negative consequences when taken out of context. With an already time-pressured day, the priority should be patients, not tweets.

Whatever your thoughts on the benefits and risks of social media, it is here to stay. Specific guidelines and guidance are needed to ensure that physicians who decide to join an online community reap the benefits of global communication,

Correspondence to M De Camp Berman Institute of Bioethics and Division of General Internal Medicine, Johns Hopkins University I 809 Ashland Avenue Baltimore MD 2I205, USA

tel +4I0 6I4 5550

e-mail

mdecampl@jhmi.edu

Correspondence to AM Cunningham

Institute of Medical Education

School of Medicine

3rd floor Neuadd Meirionydd Cardiff University, Heath Park Cardiff CFI4 4XN, Wales

tel +44 (0) $2920867 / 52$

e-mail

CunninghamAM@cardiff.ac.uk

Twitter@amcunningham

KEYWORDS Social media, ethics, professionalism, physician-patient relationship

DECLARATIONS OF INTERESTS No conflicts of interest declared.

\section{Physicians on social media: too risky for most?}

M DeCamp

With increasing numbers of physicians and patients interacting online, social media have become popular topics of conversation in the medical profession. Are social media poised to revolutionise healthcare?' Or are they a threat to medical professionalism, as evidenced by documented reports of professional misconduct online? ${ }^{2}$ In this paper I argue that, despite their popularity, social media participation is neither necessary nor appropriate for most physicians.

\section{'PATIENTS ARE THERE' IS NOT ENOUGH OF A REASON}

One commonly hears that physicians should participate in social media because their patients do, i.e. physicians should 'meet patients where they are.' Part of this is true; according to data from the United States, nearly twothirds of adults go online for health information, and just over one-third do so to understand better a medical condition. ${ }^{3}$ In other populations, more than 80 per cent of individuals go online for health information. ${ }^{4}$ These numbers are thought to be increasing. From these mere facts, however, it does not follow that physicians therefore have an obligation to meet these patients online.

Consider an analogy. The US National Assessment of Adult Literacy results suggested that non-print sources of health information, such as television and radio, were used by nearly half of survey respondents and were used more frequently than traditional print sources. ${ }^{5}$ Why then was there no major call for physicians to take to radio and television airwaves to meet patients there? Logically it does not follow that physicians are obligated to go wherever patients go to find health information. Social media are no different.

Perhaps more importantly, the aggregate fact of 'nearly two-thirds of adults' obfuscates persistent inequalities within the population related to access to these new technologies. In other words, physicians might not be 
meeting all of their patients online. This unequal access to health information could mean social media have a potential to exacerbate known health inequities or to create new ones. Commonly referred to as the 'digital divide', such inequalities exist along multiple dimensions. Adults with limited health literacy may be less likely to use digital sources. ${ }^{5}$ Elderly individuals use the internet and social media less frequently and trust it less. ${ }^{6}$ Finally, despite the potential of low cost mobile technologies to leapfrog some access disparities along traditional racial/ ethnic and socioeconomic lines, these disparities persist and are real. ${ }^{3}$ Physicians ought not treat patients differentially along these lines in other circumstances; here again, social media are no different.

\section{UNCLEAR EXPERTISE}

Even if physicians had an obligation to meet patients online, this obligation would be limited by whether physicians possess the relevant expertise to meet patients' needs in this setting. Knowing if this is true requires a clearer understanding of why patients go online and what information they seek. Recent data are illuminating. Evidence suggests that the vast majority of patients rely on offline interactions with professionals for treatment and disease-specific advice ${ }^{3}$ - the kind of interaction and advice for which physicians have relevant expertise. On the other hand, physicians are not trained to provide general health information about innumerous conditions beyond their area of specialisation. In many instances, patients who go online are doing so explicitly to find answers to questions that their physicians cannot answer (or answer best) - such as how to find a clinic, the best place to park, or where to stay during an extended treatment course. If patients are predominantly online to find helpful and practical advice from the perspective of other patients, the role of physician expertise is unclear.

Furthermore, half of the time, individuals searching for health information online are doing so on behalf of someone else. ${ }^{3}$ Although physicians undoubtedly experience this in the traditional office setting (e.g. a patient who asks a question about a loved one's health issue), this does not create an obligation to respond and to provide such information online. On the contrary, the brevity, lack of control, and permanence of online information make engaging in such activities even more risky in the online realm.

\section{UNCERTAIN PROFESSIONAL NORMS}

The above two claims cast doubt on whether physicians should generally participate on social media. They leave open the possibility of participation, however, in instances where a physician's expertise is truly relevant. Suppose a physician notices that a particular social networking website truly relates to her area of expertise. At this point, she probably should consider whether participating is the right thing to do; and in doing so, she will confront the dearth of consensus about the ethical or professional norms of behavior related to social media participation.

Despite recent efforts at developing standards of behavior on social media, ${ }^{7-9}$ the norms of appropriate behavior remain in flux. Three examples illustrate this point. First, early survey evidence suggested disagreement within the profession about whether interacting with patients online was ethically acceptable. ${ }^{10}$ In my own teaching experience, a classic yet simple question, 'should you friend a patient on Facebook?' continues to evoke a diversity of responses, vehement disagreement, and no clear consensus. Second, more recent controversy erupted when the UK's General Medical Council (GMC) recommended that physicians ought not post anonymously (i.e. whenever physicians post as physicians, they should identify themselves by name). Many disagreed with the recommendation on the basis of free speech rights, its acceptance in related spheres (e.g. pseudonyms in literature), or the necessity of anonymity in certain circumstances (e.g. whistleblowing about poor care or fraud)."

The GMC recommendation could be seen as an outlier because few other guidelines offer such specific guidance. Nevertheless, and third, even norms about which guidelines seem to agree have generated controversy. Many guidelines, for example, recommend physicians separate their personal and professional identities online. Not only do some active social media users reject this approach, but others have also questioned whether it is possible or desirable to achieve meaningful separation. ${ }^{2}$ Participation in social media has therefore become a flashpoint for a more fundamental question about defining appropriate boundaries between physicians and patients.

For a physician deciding whether to participate online, these three examples create significant confusion and doubt about whether or how to participate online in ways that do not violate professional norms. This can make not participating the most reasonable option, at least until norms becomes more widely accepted.

\section{MORE LIKELY TO MAKE MISTAKES}

A final reason physicians generally should refrain from social media is more practical. It seems reasonable to believe that users with limited social media experience are more likely to make mistakes when they use the technology. In medicine, such mistakes could lead to significant and costly harms, particularly related to breaches of physician or patient privacy and confidentiality. Imagine a physician who unwittingly and accidentally shares the sexual orientation of a colleague or patient on a social media site, reveals a particular diagnosis, or 
distributes an embarrassing photograph. Social media technologies are complicated and change rapidly; just as 'a little bit of knowledge is a dangerous thing,' so could be a little bit of dabbling in social media. Most physicians are unlikely to have the time or resources necessary to commit to developing proficiency with these technologies.

\section{CONCLUSION}

In summary, it remains unclear whether individual physicians' expertise is needed online; whether existing professional norms guide physicians sufficiently to

\section{REFERENCES}

I Mayo Clinic Center for Social Media. Bringing the social media revolution to health care [Internet]. Rochester, MN: Mayo Foundation for Medical Education and Research; 2012 [cited 20I3Nov 19]. Available from:http://network.socialmedia.mayoclinic.org/learning/ book/

2 Greysen SR, Chretien KC, Kind T et al. Physician violations of online professionalism and disciplinary actions: a national survey of state medical boards. JAMA 2012; 307:I|41-2. http://dx.doi. org/I0.I00I/jama.20I2.330

3 Fox S, Duggan M. Health online 2013 [Internet]. Washington, DC: Pew Research Center's Internet and American Life Project; 2013 [cited 20I3 November 13].Available from: http://www.pewinternet. org/ /media//Files/Reports/PIP_HealthOnline.pdf

4 Van de Belt TH, Engelen LJ, Berben SA et al. Internet and social media for health-related information and communication in health care: preferences of the Dutch general population. J Med Internet Res 2013; I5:e220. http://dx.doi.org/10.2196/jmir.2607

5 Cutilli CC, Bennett IM. Understanding the health literacy of America: results of the National Assessment of Adult Literacy. Orthop Nurs 2009; 28:27-32. http://dx.doi.org/I0.1097/0I. NOR.0000345852.22I22.d6

6 Zulman DM, Kirch M, Zheng $\mathrm{K}$ et al. Trust in the internet as a health resource among older adults: analysis of data from a nationally representative survey. J Med Internet Res 201I; I3:el9. http://dx.doi.org/10.2196/jmir.1552 minimise the risk of professional transgression; or whether physicians have the time or resources necessary to become skilled in using social media. As a result, for most physicians, the relative risks of social media participation probably outweigh their benefits.Additional focus on social media use in medical education and greater clarity and consensus regarding professional norms could change this. Until then, avid social media participation - like avid participation in television, popular press, and print media - may be best left to the experts specifically trained and supported to do so.

7 Farnan JM, Snyder Sulmasy L, Worster BK et al. Online medical professionalism: patient and public relationships: policy statement from the American College of Physicians and the Federation of State Medical Boards. Ann Intern Med 2013; I58:620-7. http:// dx.doi.org/I0.7326/0003-48|9-I58-8-20|304|60-00100

8 American Medical Association. Professionalism in the use of social media [Internet]. Chicago: AMA; 201I [cited 2013 Nov 13]. Available from: http://www.ama-assn.org/ama/pub/physicianresources/medical-ethics/code-medical-ethics/opinion9/24.page

9 General Medical Council. Doctors' use of social media [Internet]. London: GMC; 2013 [cited 2013 Nov 19]. Available from: http:// www.gmc-uk.org/Doctors_use_of_social_media.pdf_5I448306.pdf

10 Bosslet GT, Torke AM, Hickman SE et al. The patient-doctor relationship and online social networks: results of a national survey. J Gen Intern Med 20II; 26:II68-74. http://dx.doi.org//0.1007/ sI|606-0II-I76I-2

II Gunter J. The General Medical Council muzzles British doctors who want to post anonymously [Internet]. 2013 [cited 2013 Nov 14]. Available from: http://drjengunter.wordpress.com/20l3/03/3I/thegeneral-medical-council-muzzles-british-doctors-who-want-topost-anonymously/

I2 DeCamp M, Koenig TW, Chisolm MS. Social media and physicians' online identity crisis. JAMA 20I3; 310:58I-2. http://dx.doi. org/I0.100I/jama.2013.8238

\section{Physicians: top ten reasons for using social media}

AM Cunningham

\section{INTRODUCTION}

Should you have a strong social media presence? I am going to give you ten reasons why I think you need one.

Social media provides an opportunity to publish your thoughts and ideas and to share your experiences without having to go through a middleman. And many people are taking advantage of this. Globally half a billion tweets are posted every day.' Surely it must be possible to find something of value that could make it worthwhile for a doctor to start exploring these spaces? It is not nearly as difficult as you might think, because these pieces of information are not just floating unconnected to each other; they are disseminated and linked to through networks of your peers. Developing networks, and figuring out who and what to pay attention to, are some of the key learning skills we need in the twentyfirst century. ${ }^{2}$ I will convince you that it is worth developing these skills. 


\section{IO REASONS TO HAVE A SOCIAL MEDIA PRESENCE}

\section{To connect}

The landmark report on 'Health professionals for a new century' suggested that we need 'locally responsive but globally connected teams's but lamented that 'most institutions are not sufficiently outward looking to exploit the power of networking and connectivity for mutual strengthening'. ${ }^{3}$ But this is changing. It is now rare to attend a forward-thinking event without being encouraged to tweet with the conference hashtag. We are our institutions, and we are leading the way; we are making the connections.

\section{To engage}

Social media is not just about getting your message out. It is also about listening. We can learn with patient leaders. ${ }^{4}$ As Gilbert and Doughty, co-directors of the Centre for Patient Leadership, describe '[w]hen patients can both manage their own health and go on to develop the confidence and skills to lead and influence others, something special happens: new collaborative systems of healthcare take shape and positive solutions emerge to healthcare problems, locally and nationally. ${ }^{4}$ Through their blogs and tweets you can engage with them.

\section{To inform}

If you are trying to do things differently, changing the way you and your team work, where can you tell people about this? Consultant endocrinologist Partha Kar uses his blog, NHS Sugar Doc, to communicate how an award-winning team is involving patients in redesigning their service, meeting the challenges of modern healthcare. ${ }^{5}$

\section{To reflect}

Elin Roddy is a respiratory consultant. She also tweets (@elinlowri). During 'dying matters' awareness week, and prompted by discussions of end-of-life care on Twitter, she decided to write her first blog post: a reflection on how, during her working life, she has "been involved with death in many different guises and in many

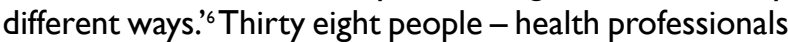
and patients - left comments to say how they had been moved by her eloquent writing. She is now lead for endof-life care in her trust and says this would not have happened without her learning through social media.

To share

In a hospital in London a patient has the wrong foot operated on because they put a compression stocking on the wrong side. The checks and balances which the nominally implemented surgical checklist should have provided did not happen.' Fortunately the other foot needed operating on too. After investigations were completed the medical director of the trust gave permission for an account to be shared through social media. The story 'Wrongfooted' by anaesthetist Helgi Johnannson has been viewed more than 17,000 times.

When surgeon and medical director, Dermot Riordan, read the story he wrote on his blog that he felt 'déjà vu, sadness and even anger'. ${ }^{8} \mathrm{~A}$ year ago nearly exactly the same mistake had occurred where he works. He describes the transparent and open approach that his team took to learning about this incident but he personally regrets that he did not share this learning with others in the way that 'Wrongfooted' showed it could be done. Social media is changing how we conceive of dissemination.

\section{To be challenged}

Often the best way to learn is to be challenged. Earlier this year people who had experienced mental health care started tweeting their experiences using the tag \#DearMentalHealthProfessionals. ${ }^{9}$ Along with appreciation and thanks there were also tweets which expressed how it felt to be let down by a system that is supposed to help. To be able to change systems for the better we need to work towards understanding, and that starts with shifting our perspectives. Social media can help us to do this.

\section{To be supported}

Sometimes we just need to know that we are not alone. \#TipsForNewDocs are short messages of advice for newly graduated medics from doctors, other health professionals and patients. Like many social media activities it is hard to say who started this trend but Guardian healthcare ${ }^{10}$ and the GMC" have both used the tag to support this important transition.

\section{To lead}

How much impact can you achieve through social media? NHS Change Day has been lauded as the 'biggest ever day of collective action to improve healthcare that started with a tweet'. ${ }^{2} A$ conversation between some junior doctors on Twitter was the catalyst for a project which saw 189,000 people take action on 13 March 2013 to improve the care of the patients they served. ${ }^{2}$

\section{To learn}

Free open access medical education - otherwise known as FOAMed $^{13}$ is on the rise. In the past we used databases to store and find these resources, but now we are increasingly depending on the power of distributed networks to help filter the best content for our needs. New educational initiatives are starting every week in social media. The case-based discussions of ECGclass ${ }^{14}$ and Gasclass for anaesthesia ${ }^{15}$ can give you a flavour of what is achievable. 


\section{To inspire}

Kate Granger is a doctor training in elderly medicine; she is also terminally ill with a rare aggressive abdominal sarcoma. During a recent hospital admission ${ }^{16}$ she noticed that too many of the staff she met did not introduce themselves. She decided that something needed to be done, so she wrote a blog post with a simple idea - when health professionals meet patients they should say 'hello, my name is'. ${ }^{17}$ People started talking about her idea and doing what she asked. The campaign has reached so many people that it is mentioned in the Government's response to the Francis Inquiry. ${ }^{18}$

\section{REFERENCES}

I Naughton J. What's Twitter's real value? Don't ask an economist. The Observer. 2013 Nov 24.

2 Rheingold H. Net smart: how to thrive online. Cambridge: MIT Press; 2012.

3 Frenk J, Chen L, Bhutta ZA et al. Health professionals for a new century: transforming education to strengthen health systems in an interdependent world. Lancet 2010; 376:1923-58. http://dx.doi. org/I0.1016/S0I40-6736(I0)6I854-5

4 Gilbert D, Doughty M. Quality: why patient leaders are the new kids on the block. Health Serv J 20I2; I22:26-7.

5 Kar P. Game-changer III: ward priority and transparency [Internet\}. Partha Kar 2013 Nov 16 [cited 2013 Nov 27].Available from: http:// nhssugardoc.blogspot.co.uk/2013/I I/game-changer-iii-wardpriority-and.html

6 Lowri E. Dying matters [Internet]. Elin Lowri 2013 May I 3 [cited 2013 Nov 27]. Available from: http://elinlowri.wordpress.com/20I3/05/I I/ dying-matters/

7 Wrongfooted [Internet]. 2013 Oct 13 [cited 2013 Nov 27]. Available from: http://storify.com/traumagasdoc/wrongfooted

8 O'Riordan D. Failure to learn [Internet]. Dermot O'Leary 2013 Oct 20 [cited 2013 Nov 27]. Available from: http://oriordan.co.uk/blog/ files/Failing\%20to\%20learn.html

9 Betton V. \#DearMentalHealthProfessionals [Internet]. Victoria Betton 2013 Aug [cited 2013 Nov 27]. Available from: http:// storify.com/VictoriaBetton/dearmentalhealthprofessionals

10 Guardian Healthcare. \#TipsForNewDocs [Internet]. 2012 [cited 2013 Nov 27]. Available from: http://storify.com/GdnHealthcare/ tipsfornewdocs

II General Medical Council. \#tipsfornewdocs [Internet]. 2013 [cited 2013 Nov 27]. Available from: http://storify.com/GMCUK/tips-fornew-doctors

\section{CONCLUSION}

Is social media a professionalism quagmire? Could your professional reputation hang on as few as 140 characters? Yes, norms are still being established but that means you can shape them. The truth is that if you respect your patients and your colleagues, like these pioneering physicians, you have little to fear. Instead, you should be feeling optimistic and excited that you can now easily tap into a global community who can help you to be a better doctor in a better system with your patients.

I2 Bevan H, Roland D, Lynton J et al. Biggest ever day of collective action to improve healthcare that started with a tweet [Internet]. 2013 June 14 [cited 2013 Nov 27]. Available from: http://www. mixprize.org/story/biggest-ever-day-collective-action-improvehealthcare-started-tweet-0

I3 Life in the fastlane. FOAM - Free Open Access Medical Education [Internet]. 2013 [cited 2013 Nov 27]. Available from: http:// lifeinthefastlane.com/foam/

14 Wetherell H. Keeping ECGs simple [Internet]. 2013 [cited 2013 Nov 27]. Available from: http://hcwetherell.blogspot.co.uk/

15 Gasclass. Gasclass: the web school of anaesthesia [Internet]. 2013 [cited 20I3 Nov 25]. Available from: http://gasclass.wordpress.com/

16 Granger K. The other side live! [Internet]. Kate Granger 2013 Aug [cited $2013 \mathrm{Nov} 27$ ].Available from:http://storify.com/katemgranger/ the-other-side-live

17 Granger K. \#hellomynameis [Internet]. Kate Granger 2013 Sept 4 [cited 2013 Nov 27]. Available from: http://drkategranger. wordpress.com/2013/09/04/hellomynameis/

I8 Department of Health. Hard truths: the journey to putting patients first. Volume one of the Government response to the Mid Staffordshire NHS Foundation Trust Public Inquiry [Internet]. London: Department of Health; 2013 [cited 2013 Nov 27]. Available from: https://www. gov.uk/government/uploads/system/uploads/attachment_data/ file/259648/34658_Cm_8754_Vol_I_accessible.pdt 